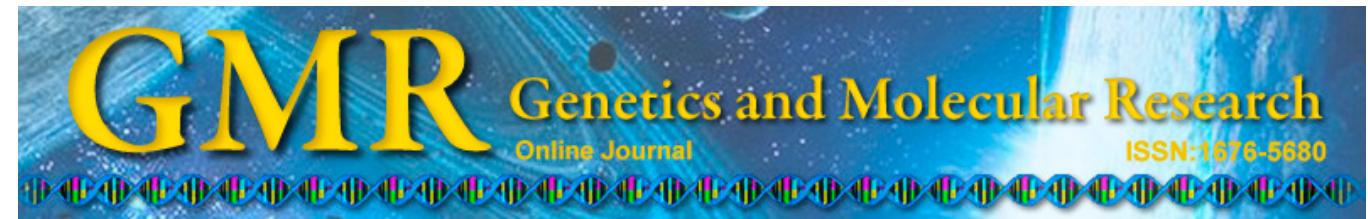

\title{
Influence of aberrant myeloid expression on acute lymphoblastic leukemia in children and adolescents from Maranhão, Brazil
}

\author{
T.C. Lopes ${ }^{1}$, K.N.S. Andrade ${ }^{1}$, N.L. Camelo ${ }^{1}$, V.P. Rodrigues ${ }^{2}$ and \\ R.A.G. Oliveira ${ }^{3}$ \\ ${ }^{1}$ Pós-Graduação em Saúde Materno-Infantil, Universidade Federal do Maranhão, \\ São Luís, MA, Brasil \\ ${ }^{2}$ Pós-Graduação em Odontologia, Universidade Federal do Maranhão, \\ São Luís, MA, Brasil \\ ${ }^{3}$ Centro de Pesquisa Clínica, \\ Hospital Universitário da Universidade Federal do Maranhão, \\ São Luís, MA, Brasil \\ Corresponding author: T.C. Lopes \\ E-mail: thaianacl@hotmail.com
}

Genet. Mol. Res. 13 (4): 10301-10307 (2014)

Received February 10, 2014

Accepted May 29, 2014

Published December 4, 2014

DOI http://dx.doi.org/10.4238/2014.December.4.25

\begin{abstract}
The aim of this study was to evaluate myeloid expression in acute lymphoblastic leukemia (ALL) in children and adolescents who had been referred to the Oncology Department in a hospital in the State of Maranhão based on demographic, laboratory, and clinical data. Myeloid expression was evaluated in 65 patients under 18 years of age who were diagnosed with morphological, cytochemical, and immunophenotypes of ALL. Demographic, laboratory (hemogram), and clinical variables were obtained from medical records. The sample was divided into groups with and without anomalous myeloid expression to analyze the variables. Myeloid expression was observed in $49.2 \%$ of the sample. Platelet count was significantly lower in the group of children without aberrant myeloid expression $\left(33,627\right.$ platelets $\left./ \mathrm{mm}^{3}, \mathrm{P}=0.01\right)$. A total of
\end{abstract}


$88.9 \%$ of children with B-cell ALL without myeloid expression showed less than 50,000 platelets $/ \mathrm{mm}^{3}(\mathrm{P}=0.01)$. Thus, platelet count may be an important parameter in the diagnosis of children with ALL without myeloid aberrant expression and may indicate a greater risk of bleeding during treatment in this group.

Key words: Acute lymphoblastic leukemia; Adolescent; Prognosis; Child; Myeloid anomalous expression; Platelet count

\section{INTRODUCTION}

Immunological classification of acute lymphoblastic leukemia (ALL) includes 3 types: B-cell ALL (B-ALL), T-cell ALL (T-ALL), and ALL + My, which involves ALL in addition to expression of myeloid antigens without scoring criteria for biphenotypic characteristics (Bene et al., 1995). The lymphoid differentiation antigens from the ALL blasts are well-defined and can be identified through immunophenotyping, using monoclonal antibodies specific for this strain criteria. ALL blasts of expressed lymphoid differentiation antigens are well-defined and can be identified through methods such as immunophenotyping using monoclonal antibodies specific for this strain criteria (Hrusák and Porwit-MacDonald, 2002). Among these markers, CD13 and CD33 are most frequently associated with aberrant myeloid expression in ALL.

CD13 is present in all stages of myeloblast maturation to granulocytes and is therefore considered to be a panmyeloid marker. CD33, which is known as a pan-AML marker, is expressed in colony-forming units of myeloblasts, promyelocytes, myelocytes, monocytes, and erythrocytes (Bacal and Faulhaber, 2003).

Among laboratory parameters used as prognostic indicators, analysis of aberrant immunophenotype expression is useful for the prognostic evaluation of children with ALL (Bhushan et al., 2010). The associations between unusual expression and other biological characteristics of the disease, such as chromosomal translocations and detection of minimal residual disease, are well established(Emerenciano etal., 2004). Studies indicate that aberrantimmunophenotypic expression can decrease the time of remission and survival in children with ALL (Kurec et al., 1991). The objective of this study was to evaluate the expression in myeloid ALL in children and adolescents referred to the Oncology Department of a hospital in the State of Maranhão based on demographic, laboratory, and clinical data.

\section{MATERIAL AND METHODS}

\section{Type of study, period, and patients}

A prospective study of 65 patients who were under 18 years old including both genders was conducted at the Instituto Maranhense de Oncologia Aldenora Belo, which is a referral center for oncology in Maranhão State, from January 2008 to September 2011.

\section{Morpho-cytochemical and immunophenotypic classification}

Bone marrow samples were sent to the Laboratory of the Clinical Research Center, University Hospital, Federal University of Maranhão (CEPEC-HU-UFMA) for morpho-cyto- 
chemical and immunophenotypic diagnosis based on French-American-British group (Bennett et al., 1976) and European Group for the Immunological Classification of Leukemias (Bene et al., 1995) criteria, respectively. Immunophenotyping and flow cytometry analysis were based on the methods of Zheng et al. (2008). The same procedures were performed for the samples obtained on day 29 (D29; end of the induction phase of treatment).

\section{Demographic, laboratory, and clinical data collection}

The date of diagnosis, age, hemoglobin dosage, and leukocyte and platelet counts were determined. On D29, the patients were evaluated and assigned to 1 of 2 groups: remission and no remission or death. Remission and non-remission was considered when patients had less and more than 5\% blasts in the bone marrow, respectively. Such information was obtained from medical records of the Instituto Maranhense de Oncologia Aldenora Belo. The classification into risk groups at diagnosis was based on the GBTLI-99 protocol (Sociedade Brasileira de Oncologia Pediátrica, 2000).

\section{Aberrant myeloid expression classification}

Myeloid aberrant expression was determined using flow cytometry to identify ALL markers and the expression of CD13 and/or CD33, without criteria for acute biphenotypic leukemia. The patients were divided into 2 groups: with (ALL/My+) and without abnormal myeloid expression (ALL/My-) based on the demographic, clinical, and laboratory variables described above.

\section{Statistical analysis and ethical criteria}

Statistical analysis was performed using the Epi-Info statistical software (Centers for Disease Control and Prevention, Atlanta, GA, USA). The Fisher exact test and the Mann-Whitney test were also used. The level of significance was set at $5 \%(\mathrm{P}<0.05)$. This study was approved by the Ethics and Research Committee of Hospital Universitário from UFMA, under the Opinion No. 115/2008. Parents or guardians of the study participants signed informed consent forms.

\section{RESULTS}

Of the 65 patients, 32 (49.2\%) expressed at least 1 myeloid antigen (CD13 or CD33), while 33 (50.8\%) expressed neither these markers. The relationship between ALL/My+ and ALL/My- and the study variables was statistically significant for platelets $(\mathrm{P}=0.01)$, indicating a lower mean value in the group of children without myeloid aberrant expression $(33,627 /$ $\left.\mathrm{mm}^{3}\right)$ compared to the group with this marker $\left(71,959 / \mathrm{mm}^{3}\right)$. Other variables showed no significant results (Table 1).

Based on stratification of laboratory data for leukocytes, hemoglobin, and platelets, most children with the B immunophenotype showed values lower than 10,000 leukocytes/ $\mathrm{mm}^{3}$ (48.1\% B-ALL/My+ and 66.7\% B-ALL/My-). In T-ALL, no patient showed less than 10,000 leukocytes $/ \mathrm{mm}^{3}$, but $60 \%$ of patients showed T-ALL/My+ and $50 \%$ of B-ALL/My- 
showed hyperleukocytosis with more than 50,000 leukocytes $/ \mathrm{mm}^{3}$. These results were not significant ( $\mathrm{P}>0.05$; Table 2). Most individuals with B-ALL had moderate anemia, as indicated by hemoglobin levels of 7-10 g/dL, both in the group with abnormal expression (63.0\%) and in the group without phenotypic expression (55.9\%). In T-ALL, $40 \%$ of children showing $\mathrm{My}+$ expression and $50 \%$ of those without $\mathrm{My}+$ expression were in this stratum for hemoglobin. $\mathrm{P}$ values in this group were not significant $(\mathrm{P}>0.05$; Table 2).

\begin{tabular}{|c|c|c|c|}
\hline Variables & $\mathrm{ALL} / \mathrm{My}+(\mathrm{N}=32)$ & ALL/My- $(\mathrm{N}=33)$ & $\mathrm{P}$ value \\
\hline Age (years, means $\pm \mathrm{SD}$ ) & $6.8 \pm 4.1$ & $6.2 \pm 4.7$ & 0.22 \\
\hline Gender (N; \%) & & & 0.42 \\
\hline Male & $23 ; 71.9$ & $22 ; 66.7$ & \\
\hline Female & $9 ; 28.1$ & $11 ; 33.3$ & \\
\hline ALL subtype (N; \%) & & & 0.52 \\
\hline B-ALL & $27 ; 84.4$ & $27 ; 81.8$ & \\
\hline T-ALL & $5 ; 15.6$ & $6 ; 18.2$ & \\
\hline Blast's morphology (N; \%) & & & 0.39 \\
\hline L1 & $30 ; 93.8$ & $29 ; 87.9$ & \\
\hline L2 & $2 ; 6.3$ & $3 ; 9.1$ & \\
\hline L3 & $0 ; 0$ & $1 ; 3.0$ & \\
\hline \multicolumn{4}{|l|}{ Risk group (N; \%) } \\
\hline High & $15 ; 46.9$ & $13 ; 39.4$ & 0.33 \\
\hline Low & $17 ; 53.1$ & $20 ; 60.3$ & \\
\hline \multicolumn{4}{|l|}{ D29 (N; \%) } \\
\hline Remission & $25 ; 78,1$ & $22 ; 66,7$ & 0.22 \\
\hline Non-remission or death & $7 ; 21,9$ & $11 ; 33,3$ & \\
\hline Blasts BM (means \pm SD) & $81.6 \pm 19.8$ & $70.8 \pm 23.4$ & 0.05 \\
\hline Blasts PB (means $\pm \mathrm{SD}$ ) & $50.3 \pm 35.0$ & $43.0 \pm 32.2$ & 0.37 \\
\hline Leukocytes $/ \mathrm{mm}^{3}($ means $\pm \mathrm{SD})$ & $35,109 \pm 40,999$ & $29,719 \pm 42,773$ & 0.31 \\
\hline Hemoglobin $(\mathrm{g} / \mathrm{dL} ;$ means $\pm \mathrm{SD})$ & $8.4 \pm 2.1$ & $8.1 \pm 2.4$ & 0.53 \\
\hline Platelets $/ \mathrm{mm}^{3}($ means $\pm \mathrm{SD})$ & $71,959 \pm 72,552$ & $33,627 \pm 30,442$ & $0.01 *$ \\
\hline
\end{tabular}

$\mathrm{ALL} / \mathrm{My}+=$ acute lymphoblastic leukemia with myeloid anomalous expression. ALL/My- $=$ acute lymphoblastic leukemia without myeloid anomalous expression; B-ALL = ALL B immune subtype; T-ALL = ALL T immune subtype; $\mathrm{BM}=$ bone marrow; $\mathrm{PB}=$ pheriperal blood; $\mathrm{D} 29=$ end of the induction phase of treatment. *Statistically significant difference $(\mathrm{P}<0.05)$.

Table 2. Distribution of patients with B-ALL and T-ALL with and without anomalous myeloid expression according to hematological data.

\begin{tabular}{|c|c|c|c|c|c|c|}
\hline \multirow[t]{2}{*}{ Variables } & \multicolumn{2}{|c|}{ B-ALL $(\mathrm{N}=54)$} & \multirow[t]{2}{*}{$\mathrm{P}$ value } & \multicolumn{2}{|c|}{ T-ALL $(\mathrm{N}=11)$} & \multirow[t]{2}{*}{$P$ value } \\
\hline & $\mathrm{My}+(\mathrm{N}=27)$ & My- $(\mathrm{N}=27)$ & & $\mathrm{My}+(\mathrm{N}=5)$ & My- $(N=6)$ & \\
\hline Leukocytes (N; \%) & & & 0.38 & & & 0.60 \\
\hline$<10,000 / \mathrm{mm}^{3}$ & $13 ; 48.1$ & $18 ; 66.7$ & & $0 ; 0$ & $0 ; 0$ & \\
\hline $10,000-50,000 / \mathrm{mm}^{3}$ & $8 ; 29.6$ & $5 ; 18.5$ & & $2 ; 40.0$ & $3 ; 50.0$ & \\
\hline$>50,000 / \mathrm{mm}^{3}$ & $6 ; 22.2$ & $4 ; 14.8$ & & $3 ; 60.0$ & $3 ; 50.0$ & \\
\hline Hemoglobin (N; \%) & & & 0.64 & & & 0.67 \\
\hline$<7 \mathrm{~g} / \mathrm{dL}$ & $6 ; 22.2$ & $9 ; 33.3$ & & $2 ; 40.0$ & $1 ; 16.7$ & \\
\hline $7-10 \mathrm{~g} / \mathrm{dL}$ & $17 ; 63.0$ & $14 ; 55.9$ & & $2 ; 40.0$ & $3 ; 50.0$ & \\
\hline$>10 \mathrm{~g} / \mathrm{dL}$ & $4 ; 18.8$ & $4 ; 14.8$ & & $1 ; 20.0$ & $2 ; 33.3$ & \\
\hline Platelets (N; \%) & & & $0.01 *$ & & & 0.88 \\
\hline$<50,000 / \mathrm{mm}^{3}$ & $15 ; 55.6$ & $24 ; 88.9$ & & $3 ; 60.0$ & $3 ; 50.0$ & \\
\hline $50,000-100,000 / \mathrm{mm}^{3}$ & $5 ; 18.5$ & $2 ; 7.4$ & & $1 ; 20.0$ & $2 ; 33.3$ & \\
\hline$>100,000 / \mathrm{mm}^{3}$ & $7 ; 25.9$ & $1 ; 3.7$ & & $1 ; 20.0$ & $1 ; 16.7$ & \\
\hline
\end{tabular}

$\mathrm{My}+=$ positive myeloid anomalous expression; My- = negative myeloid anomalous expression. *Statistically significant difference $(\mathrm{P}<0.05)$. 
Only 1 patient (3.7\%) with B-ALL/My- presented over 100,000 platelets $/ \mathrm{mm}^{3}$, while $7(25.9 \%)$ in the B-ALL/My+ group were in this category. Platelet counts differed significantly between patients with B-ALL/My- and B-ALL/My+ $(\mathrm{P}=0.01)$. This was not observed in patients with T-ALL (Table 2), although our sample was small for this leukemia immunological type. This result is noted in Table 3. For leukocytes, platelets, and hemoglobin, the average $\mathrm{P}$ values in the assessment of platelets between B-ALL/My+ and B-ALL-/My- was 0.02, and the B-ALL/My+ group had an average value of 72,274 platelets $/ \mathrm{mm}^{3}$; this was higher than the average value for platelets in the B-ALL/My- group, which was 27,726 platelets $/ \mathrm{mm}^{3}$ (Table 3 ).

$\begin{aligned} & \text { Table 3. Distribution of B-ALL patients with and without anomalous myeloid expression according to } \\
& \text { hematological data. }\end{aligned}$
\begin{tabular}{lccc}
\hline Variables & $\begin{array}{c}\text { B-ALL/My+ }(\mathrm{N}=27) \\
(\text { means } \pm \mathrm{SD})\end{array}$ & $\begin{array}{c}\text { B-ALL/My- }(\mathrm{N}=27) \\
(\text { means } \pm \mathrm{SD})\end{array}$ & P value \\
\hline Leukocytes $\left(/ \mathrm{mm}^{3}\right)$ & $30,796 \pm 41,862$ & $19,485 \pm 28,525$ & 0.19 \\
Hemoglobin $(\mathrm{g} / \mathrm{dL})$ & $8.44 \pm 1.78$ & $7.98 \pm 2.37$ & 0.29 \\
Platelets $\left(/ \mathrm{mm}^{3}\right)$ & $72,274 \pm 76,576$ & $27,726 \pm 21,705$ & $0.02^{*}$ \\
\hline
\end{tabular}

$\mathrm{B}-\mathrm{ALL} / \mathrm{My}+=\mathrm{B}-\mathrm{ALL}$ with anomalous myeloid expression; B-ALL/My- = B-ALL without anomalous myeloid expression. *Statistically significant difference $(\mathrm{P}<0.05)$.

\section{DISCUSSION}

The frequency of aberrant myeloid expression in ALL identified in this study (49.2\%) was similar to the $46.67 \%$ previously identified in Brazilian patients by Emerenciano et al. (2004) and in other locations, including $49 \%$ by Kurec et al. (1991), 52.4\% by Bachir et al. (2009), and $53.2 \%$ by Tanyeli et al. (2010). Other Brazilian studies indicate a frequency of approximately $31 \%$ (Valle, 2002; da Silva et al., 2004). Lower frequencies were identified by Wiersma et al. (1991), Bhushan et al. (2010), and Shen et al. (2003), with 22, 23, and 27\%, respectively. These discordant results may be because of the known genetic influence on the leukemia immunophenotype (Emerenciano et al., 2004) and because children were evaluated at different locations.

Studies examining the impact of aberrant myeloid expression on the prognosis of ALL are controversial. A previous study suggested that ALL/My+ is not useful for predicting prognosis (Putti et al., 1998). However, others identified an association between myeloid expression and a reduction in time to first remission, indicating poor prognosis (Pui et al., 1990; Kurec et al., 1991).

Excluding the study of the immune type of ALL (B or T), few studies have assessed the relationship between aberrant myeloid expression and other variables at the time of diagnosis of ALL. Age, gender, French-American-British group morphology of blasts, the percentage of blasts in peripheral blood, leukocytes, and hemoglobin were not significant factors in this study, which was similar to the results of a previous study (Kurec et al., 1991). In both studies, the results were similar in both groups (anomalous and non-anomalous), except that the average number of leukocytes in this study was lower $\left(35,109\right.$ leukocytes $/ \mathrm{mm}^{3}$ in the group with aberrant expression and 29,719 leukocytes $/ \mathrm{mm}^{3}$ in the group without aberrant expression) (Table 1).

In agreement with our results, Tanyeli et al. (2010) also did not find a statistical difference between groups and in the morphology of the blasts. However, other studies reported an association between aberrant expression and L2 blast morphology (Wiersma et al., 1991). In the risk group on D29, the percentage of blasts in the peripheral blood and bone marrow was also 
not significant in this study, but the latter value for the 2 groups was nearly significant $(\mathrm{P}=0.05)$ (Table 1), with a higher blast count in the bone marrow in the group with abnormal expression $(81.6 \%)$. Only 1 study involving adults has evaluated these variables, in which the blast count in the peripheral blood was greater in the non-anomalous group (Vitale et al., 2007).

Analysis of the immune profile of ALL revealed no statistically significant difference between the B and T phenotypes (Table 1); this was also observed by Bachir et al. (2009) and Rêgo (2002). The absence of anomalous expression in T-ALL (Bhushan et al., 2010) and the positive clinical significance of the aberrant phenotype when evaluating B-ALL for minimal residual disease (Seegmiller et al., 2009), an important parameter used to assess the risk of recurrence after the first induction phase in the treatment of ALL, has been reported previously. According to Baruchel et al. (1997), there is a higher incidence of myeloid expression in B-ALL because of chromosomal translocations and aberrant gene fusions, which is frequently observed in B lineage progenitor cells in children, while this is not observed in adults.

In this study, we measured mean platelet count $\left(33,627\right.$ platelets $/ \mathrm{mm}^{3}$ in the group without aberrant myeloid expression and 71,959 platelets $/ \mathrm{mm}^{3}$ in the group with this marker, $\mathrm{P}=0.01$ ) (Table 1). da Silva et al. (2004) found no statistical difference in this analysis in Paraná State, a result also observed in other studies (Kurec et al., 1991; Wiersma et al., 1991; Bhushan et al., 2010). Vitale et al. (2007) observed similar results in adults, were the group with myeloid expression presented a higher platelet count. Similar result, as observed in this study in adults, showed a higher platelet value in the group with increased myeloid expression (Vitale et al., 2007).

Based on the stratification of platelets, children with B-ALL showed significant differences $(\mathrm{P}=0.01)$, with the largest number of individuals with B-ALL/My- $(88.9 \%)$ showing fewer than 50,000 platelets $/ \mathrm{mm}^{3}$ and only $3.7 \%$ with a platelet count greater than 100,000 / $\mathrm{mm}^{3}$ (Table 2). Of children with B-ALL/My+, 55.6\% had less than 50,000 platelets $/ \mathrm{mm}^{3}$ and $25.9 \%$ had counts over $100,000 / \mathrm{mm}^{3}$. This difference was not observed in children with TALL, likely because of the small sample size $(\mathrm{N}=11)$. A significant difference was confirmed in B-ALL patients based on the evaluation of the average platelet count, in which B-ALL/My+ patients showed statistically significant values $\left(72,274\right.$ platelets $\left./ \mathrm{mm}^{3}\right)$ compared to B-ALL-/ My- patients $\left(27,726\right.$ platelets $\left./ \mathrm{mm}^{3}\right)$ at $\mathrm{P}=0.02$ (Table 3 ).

Determining the platelet count when treating children with ALL is important. Because of the lifetime of platelets in the circulation (8-10 days), a lower platelet count in the blood of patients diagnosed with acute leukemia shows a high proliferative power of the leukemic clone (Oliveira, 2007). In addition, because of changes in capillary fragility secondary to inflammation, fewer than 50,000 platelets $/ \mathrm{mm}^{3}$ in patients with infection can lead to hemorrhage, characterized by epistaxis, gingival, gastrointestinal bleeding, and central nervous system bleeding, leading to the need for transfusion therapy and supportive care for children with ALL (Sociedade Brasileira de Oncologia Pediátrica, 2000).

Although children with acute leukemia and aberrant myeloid expression have low platelet counts, our results suggest that a statistical difference exists compared to the nonanomalous group $(\mathrm{P}=0.01)$, revealing a less aggressive clinical picture, and a lower chance of bleeding during treatment. Molecular studies are required to identify genetic factors that may influence platelet count in individuals with and without aberrant myeloid immunophenotypic expression. Our results may contribute to improvements in the medical management and treatment of childhood ALL in Maranhão by assessing the risks of thrombocytopenia in children without aberrant myeloid expression during diagnosis. 


\section{ACKNOWLEDGMENTS}

The authors would like to acknowledge all the children and adolescents who participated in this study and the staff from the Archive and medical group of the Oncopediatrics service from the Instituto Maranhense de Oncologia Aldenora Belo for providing the data.

\section{REFERENCES}

Bacal NS and Faulhaber MHW (2003). Aplicação Prática em Citometria de Fluxo. Atheneu, São Paulo.

Bachir F, Bennani S, Lahjouji A, Cherkaoui S, et al. (2009). Characterization of acute lymphoblastic leukemia subtypes in Moroccan children. Int. J. Pediatr. 1-7.

Baruchel A, Cayuela JM, Ballerini P, Landman-Parker J, et al. (1997). The majority of myeloid-antigen-positive (My+) childhood B-cell precursor acute lymphoblastic leukaemias express TEL-AML1 fusion transcripts. Br. J. Haematol. 99: 101-106.

Bene MC, Castoldi G, Knapp W, Ludwig WD, et al. (1995). Proposals for the immunological classification of acute leukemias. European Group for the Immunological Characterization of Leukemias (EGIL). Leukemia 9: 1783-1786.

Bennett JM, Catovsky D, Daniel MT, Flandrin G, et al. (1976). Proposals for the classification of the acute leukaemias. French-American-British (FAB) co-operative group. Br. J. Haematol. 33: 451-458.

Bhushan B, Chauhan PS, Saluja S, Verma S, et al. (2010). Aberrant phenotypes in childhood and adult acute leukemia and its association with adverse prognostic factors and clinical outcome. Clin. Exp. Med. 10: 33-40.

da Silva IZ, Bom APKP, Parise GA, Malvezzi M, et al. (2004). Expressão dos marcadores mielóides e prognóstico das leucemias linfóides agudas. Pediatria 26: 97-103.

Emerenciano M, Bossa Y, Zanrosso CW, Alencar DM, et al. (2004). Frequência de imunofenótipos aberrantes em leucemias agudas. Rev. Bras. Cancerol. 50: 183-189.

Hrusák O and Porwit-MacDonald A (2002). Antigen expression patterns reflecting genotype of acute leukemias. Leukemia 16: $1233-1258$

Kurec AS, Belair P, Stefanu C, Barrett DM, et al. (1991). Significance of aberrant immunophenotypes in childhood acute lymphoid leukemia. Cancer 67: 3081-3086.

Oliveira RAG (2007). Hemograma: Como Fazer e Interpretar. Livraria Médica Paulista, São Paulo.

Pui CH, Behm FG, Singh B, Rivera GK, et al. (1990). Myeloid-associated antigen expression lacks prognostic value in childhood acute lymphoblastic leukemia treated with intensive multiagent chemotherapy. Blood 75: 198-202.

Putti MC, Rondelli R, Cocito MG, Arico M, et al. (1998). Expression of myeloid markers lacks prognostic impact in children treated for acute lymphoblastic leukemia: Italian experience in AIEOP-ALL 88-91 studies. Blood 92: 795-801.

Rêgo MFN (2002). Características das leucemias agudas em Teresina. Master's thesis, Universidade Estadual de Campinas, UEC, Campinas.

Seegmiller AC, Kroft SH, Karandikar NJ and McKenna RW (2009). Characterization of immunophenotypic aberrancies in 200 cases of B acute lymphoblastic leukemia. Am. J. Clin. Pathol. 132: 940-949.

Shen HQ, Tang YM, Yang SL, Qian BQ, et al. (2003). Immunophenotyping of 222 children with acute leukemia by multicolor flow cytometry. Zhonghua Er. Ke Za Zhi 41: 334-337.

Sociedade Brasileira de Oncologia Pediátrica (2000). GBTLI LLA-99: Protocolo de Tratamento da Leucemia Linfóide Aguda em Crianças. SBOP, Campinas.

Tanyeli A, Erbey F, Bayram I and Komur M (2010). Myeloid antigen positivity in Turkish children with acute lymphoblastic leukemia lacks influence on prognosis. Asian Pac. J. Cancer Prev. 11: 1823-1826.

Valle C (2002). Prognostic value of myeloid-associated antigen expression (CD13 and/or CD33) in childhood acute lymphoblastic leukemia. Med. Pediatr. Oncol. 39: 217-472.

Vitale A, Guarini A, Ariola C, Meloni G, et al. (2007). Absence of prognostic impact of CD13 and/or CD33 antigen expression in adult acute lymphoblastic leukemia. Results of the GIMEMA ALL 0496 trial. Haematologica 92: 342-348.

Wiersma SR, Ortega J, Sobel E and Weinberg KI (1991). Clinical importance of myeloid-antigen expression in acute lymphoblastic leukemia of childhood. N. Engl. J. Med. 324: 800-808.

Zheng J, Wang X, Hu Y, Yang J, et al. (2008). A correlation study of immunophenotypic, cytogenetic, and clinical features of 180 AML patients in China. Cytometry B Clin. Cytom. 74: 25-29. 